\title{
Obituario
}

\section{Dr. Jorge Arana Carvalho}

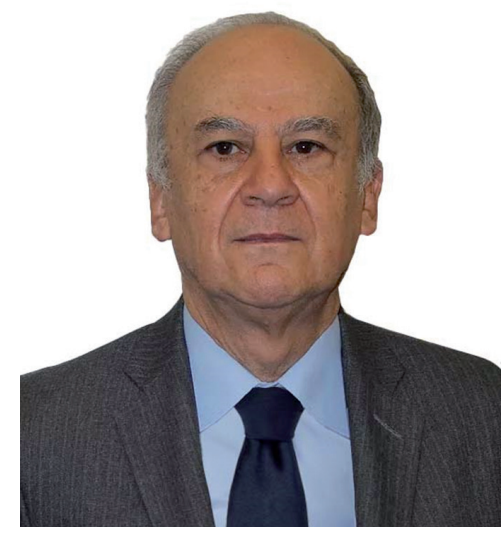

26 de octubre de 1949 † 24 de septiembre de 2021

Se me "arruga" el corazón al enterarme del fallecimiento de otro de los integrantes del servicio de neurocirugía de nuestro Hospital de San José, el doctor Jorge Arana Carvalho. Nació en Pitalito, Huila, el 26 de octubre de 1949 en el hogar de Salvador Arana y Belén Carvalho.

Los estudios de medicina los inició en 1967 en la facultad de medicina de la Universidad Nacional y obtuvo el grado como médico cirujano en 1974, habiendo hecho previamente el llamado rural en los hospitales San José de Sogamoso y San Vicente de Génova, Quindío.

Conocí a Jorge hacia el año de 1976, cuando ingresó a nuestro servicio de neurocirugía para iniciar su entrenamiento y al finalizarlo viajó en 1980 a Gainesville (Florida) al servicio de neurocirugía del profesor Rhoton y luego fue a Alemania al servicio del profesor Herrman, permaneciendo allá durante 1981 y 1982, profundizando en la cirugía de columna y en microcirugía.
Compartí con Jorge durante los muchos años de vinculación con San José, las múltiples experiencias clínicas y quirúrgicas, las mejores oportunidades para tratamiento exitoso de los pacientes y me comentaba con lujo de detalles su experiencia durante su estadía en Alemania.

Siempre me manifestó su preocupación por el devenir del servicio del que fue jefe entre 1991 y 1993. No le gustaba usar el microscopio quirúrgico y prefería sus lentes de aumento, con los que se desenvolvía a las mil maravillas. Compartió Jorge su actividad neuroquirúrgica en los hospitales San Ignacio de la Universidad Javeriana durante algunos años, en el Hospital de Occidente Kennedy y hasta pocos días antes de enfermarse en el Hospital de San José. Nuestra comunicación fue muy frecuente y la tuvimos hasta sus últimos días telefónicamente, durante su hospitalización.

Con su esposa Amine Fleifel construyó su hogar del que nacieron los hijos Riad y Hannan, prestigiosos médicos que

\section{INFORMACIÓN DEL ARTÍCULO}

Historia del artículo:

Fecha recibido: octubre 8 de 2021

Fecha aceptado: octubre 8 de 2021
Autor para correspondencia.

Manuel Roberto Palacios P. mrpalacios@fucsalud.edu.co
DOI

10.31260/RepertMedCir.01217372.1290 
ejercen en Francia, Hannan es anestesióloga y Riad patólogo. Su gran capacidad para aprender idiomas le permitió además de su lenguaje nativo hablar inglés, francés y alemán.

Fue docente de neurocirugía en la facultad de medicina de la Universidad Javeriana de 1983 a 1988, profesor asistente de la Universidad del Rosario y luego profesor titular de la Fundación Universitaria de Ciencias de la Salud hasta 2021. Su dedicación con los estudiantes y residentes en entrenamiento fue permanente y valorada por ellos como excelente, dada su gran disponibilidad.

Fue miembro de la Asociación Colombiana de Neurocirugía y de la Deutscher Academuscher Austtauschdienst de Alemania. La Sociedad de Cirugía de Bogotá, Hospital de San José, lo distinguió en el año 2014 con la orden de la Cruz de Honor y en 2021 con la orden de Cruz de Plata.
Entre varias publicaciones como autor o coautor se encuentran Tumores silenciosos del sistema nervioso central, Aneurismas cerebrales gigantes, Trauma encéfalocraneano, Pautas de diagnóstico y tratamiento neurológico, Manual de microcirugía y Meningiomas gigantes.

No me queda la menor duda que, por su gran don de gentes apreciado por colegas y amistades, el fallecimiento de Jorge haya causado honda pena, pero estoy seguro de que ocupa un lugar privilegiado en su nueva morada.

Paz en ella.

Manuel Roberto Palacios P. Neurocirujano

Secretario General Fundación Universitaria de Ciencias de la Salud. 